\title{
Monetary cost of self-reported diet in relation to biomarker- based estimates of nutrient intake in young Japanese women
}

\author{
Kentaro Murakami ${ }^{1}$, Satoshi Sasaki ${ }^{1, *}$, Yoshiko Takahashi ${ }^{2}$, Kazuhiro Uenishi $^{3}$ and the \\ Japan Dietetic Students' Study for Nutrition and Biomarkers Group† \\ 'Department of Social and Preventive Epidemiology, School of Public Health, University of Tokyo, Hongo 7-3-1, \\ Bunkyo-ku, Tokyo 113-0033, Japan: ${ }^{2}$ Department of Health and Nutrition, School of Home Economics, Wayo \\ Women's University, Chiba, Japan: ${ }^{3}$ Laboratory of Physiological Nutrition, Kagawa Nutrition University, \\ Saitama, Japan
}

Submitted 7 May 2008: Accepted 15 September 2008: First published online 14 November 2008

\begin{abstract}
Objective: All previous studies on monetary diet cost have examined the relationship of monetary cost of self-reported diet to self-reported, rather than biomarker-based, estimates of dietary intake. The present cross-sectional study examined the association between monetary costs of self-reported diet and biomarker-based estimates of nutrient intake.

Design: Monetary diet cost (Japanese yen/1000 kJ) was calculated based on dietary intake information from a self-administered, comprehensive diet history questionnaire using retail food prices. Biomarker-based estimates of nutrient intake (percentage of energy for protein and $\mathrm{mg} / 1000 \mathrm{~kJ}$ for $\mathrm{K}$ and $\mathrm{Na}$ ) were estimated based on $24 \mathrm{~h}$ urinary excretion and estimated energy expenditure. Setting: A total of fifteen universities and colleges in Japan.

Subjects: A total of 1046 female Japanese dietetic students aged 18-22 years.

Results: Total monetary diet cost showed a significant positive association with biomarker-based estimates of protein, $\mathrm{K}$ and $\mathrm{Na}$. Vegetables and fish were not only the main contributors to total monetary diet cost $(16 \cdot 4 \%$ and $15 \cdot 5 \%$, respectively) but also were relatively strongly correlated with total monetary diet cost (Pearson's correlation coefficient: $0 \cdot 70$ and $0 \cdot 68$, respectively). Monetary cost of vegetables was significantly positively associated with all three nutrients, while that of fish showed a significant and positive association only with protein.

Conclusions: Total monetary cost of self-reported diet was positively associated with biomarker-based estimates of protein, $\mathrm{K}$ and $\mathrm{Na}$ intake in young Japanese women, and appeared mainly to be explained by the monetary costs of vegetables and fish.
\end{abstract}

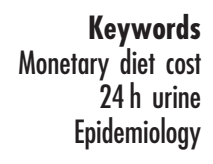

While food choice is influenced by a large number of factors ${ }^{(1)}$, the price of food is clearly an important

\footnotetext{
$\dagger$ The members of the Japan Dietetic Students' Study for Nutrition and Biomarkers Group (in addition to the authors) are as follows: Mitsuyo Yamasaki, Yuko Hisatomi, Junko Soezima and Kazumi Takedomi (Nishikyushu University); Toshiyuki Kohri and Naoko Kaba (Kinki University); Etsuko Uneoka (Otemae College of Nutrition); Hitomi Hayabuchi and Yoko Umeki (Fukuoka Women's University); Keiko Baba and Maiko Suzuki (Mie Chukyo University Junior College); Reiko Watanabe and Kanako Muramatsu (Niigata Women's College); Kazuko Ohki, Seigo Shiga, Hidemichi Ebisawa and Masako Fuwa (Showa Women's University); Tomoko Watanabe, Ayuho Suzuki and Fumiyo Kudo (Chiba College of Health Science); Katsumi Shibata, Tsutomu Fukuwatari and Junko Hirose (The University of Shiga Prefecture); Toru Takahashi and Masako Kato (Mimasaka University); Toshinao Goda and Yoko Ichikawa (University of Shizuoka); Junko Suzuki, Yoko Niida, Satomi Morohashi, Chiaki Shimizu and Naomi Takeuchi (Hokkaido Bunkyo University); Jun Oka and Tomoko Ide (Tokyo Kasei University); and Yoshiko Sugiyama and Mika Furuki (Minamikyushu University).
}

determinant $^{(2,3)}$. Generally, energy-dense and nutrientdilute foods such as cereals, fats and oils, and sugar and sweets provide dietary energy at lowest cost. Conversely, the cost per kilojoule of energy-dilute and nutrient-dense foods, including vegetables, fish and fruit, is much higher. If healthier foods cost more then so too will healthier diets. In fact, several ${ }^{(4-9)}$ although not all ${ }^{(10)}$ observational studies have shown that healthful diets are more expensive than less healthful diets.

However, all of these previous studies have estimated both monetary diet costs and dietary intake based on selfreported dietary intake obtained by the same dietary assessment method, resulting in an inevitable overestimation of the association between monetary diet cost and dietary intake due to errors shared by monetary diet costs and dietary intake. Given the difficulty in estimating 
monetary diet cost at the individual level without dietary intake information $^{(11)}$ as well as the existence of valid biomarkers for dietary intake of several nutrients ${ }^{(12-16)}$, the combined use of monetary diet cost estimated from selfreported dietary intake information and biomarker-based estimates of dietary intake is an attractive alternative methodology for this important public health issue.

The Japan Dietetic Students' Study for Nutrition and Biomarkers $^{(17-19)}$ is unique in that both estimates of monetary cost of self-reported diet and urine biomarkerbased estimates of dietary intake are available (although blood biomarkers of dietary intake are unfortunately unavailable due to limited financial resources). In the current preliminary report, we used this data set to investigate the association of monetary diet cost ${ }^{(10)}$ estimated from a selfadministered, comprehensive diet history questionnaire $(\mathrm{DHQ})^{(20-23)}$ with biomarker-based estimates of dietary protein ${ }^{(12,13)}, \mathrm{K}^{(14,15)}$ and $\mathrm{Na}^{(14,16)}$ obtained from $24 \mathrm{~h}$ urinary excretion.

\section{Subjects and methods}

\section{Subjects}

The present study was based on a cross-sectional multicentre survey conducted from February to March 2006 and from January to March 2007 among female dietetic students from fifteen institutions in Japan. Detailed descriptions of the survey have been published elsewhere ${ }^{(17-19)}$. Briefly, staff at each institution provided an outline of the survey to potential subjects. Those who agreed to participate were then provided detailed written and oral explanations of the survey's general purpose and procedure. A total of 1176 Japanese women took part. All measurements at each institution were conducted according to the survey protocol. The study protocol was approved by the Ethics Committee of the National Institute of Health and Nutrition, Japan. Written informed consent was obtained from each subject, and also from a parent for subjects aged $<20$ years.

\section{Monetary diet cost}

Dietary habits during the preceding month were assessed using a self-administered, comprehensive DHQ. Detailed descriptions of the DHQ concerning its structure, calculation of dietary intake and validity for commonly studied nutritional factors have been published elsewhere ${ }^{(20-23)}$. Responses to the DHQ were checked at least twice for completeness by trained survey staff (mostly registered dietitians) and, when necessary, forms were reviewed with the subject to ensure the clarity of answers. Briefly, the DHQ is a 16-page structured questionnaire which asks about the consumption frequency and portion size of selected foods commonly consumed in Japan as well as general dietary behaviour and usual cooking methods ${ }^{(20)}$. Estimates of daily intake for foods (150 items in total) and energy were calculated using an ad boc computer algorithm for the $\mathrm{DHQ}^{(20,23)}$, which was based on the Standard Tables of Food Composition in Japan ${ }^{(24)}$.

Monetary cost of the habitual diet (Japanese yen/d) was calculated by multiplying the amount of each food estimated from the DHQ $(\mathrm{g} / \mathrm{d})$ by the estimated price of the food (Japanese yen/g) and summing the products ( 1 Japanese yen $=0.0048 \mathrm{GBP}=0.0062 €=0.0095$ \$US in May 2008). A detailed description of the cost calculation method as well as the monetary cost of each food has been published elsewhere ${ }^{(10)}$. Briefly, the price of each food was determined based on the National Retail Price Survey $2004^{(25)}$. For foods whose price was not published in the survey (thirteen items), prices were taken from the websites of a nationally distributed supermarket (Seiyu, Tokyo, Japan) or fast-food restaurant (McDonalds, Tokyo, Japan and Mister Donut, Tokyo, Japan) chain. Alcoholic beverages (six items), non-caloric beverages (four items) and water (three items) were excluded from calculation $^{(4)}$. Costs of combined foods such as pizza were calculated using the prices of frozen equivalents ${ }^{(9)}$. The procedure for estimating costs was based on the assumption that all foods were purchased and then prepared and consumed at home ${ }^{(11)}$.

While the misreporting of dietary intake, a serious problem associated with self-report dietary assessment methods, is strongly associated with BMI not only in Western populations with relatively high mean $\mathrm{BMI}^{(26)}$ but also in Japanese populations with relatively low mean $\mathrm{BMI}^{(17)}$, BMI-dependent misreporting seems to be cancelled by energy adjustment, at least for protein, $\mathrm{K}$ and $\mathrm{Na}^{(17)}$. Energy-adjusted values of total monetary diet cost as well as the monetary cost of selected food groups (Japanese yen/1000 kJ) were thus calculated by dividing the estimated monetary cost (Japanese yen/d) by the total energy intake $(\mathrm{kJ} / \mathrm{d})$ and multiplying by 1000 . Categorization of food groups has been published elsewhere ${ }^{(10)}$.

\section{Biomarker-based estimate of nutrient intake}

Within 1-3d after completion of the questionnaires, a single $24 \mathrm{~h}$ urine collection was performed. Detailed descriptions of the procedure of $24 \mathrm{~h}$ urine collection have been published elsewhere ${ }^{(17,19)}$. Briefly, subjects were provided with three or four 1-litre bottles (containing no additives), ten $400 \mathrm{ml}$ cups marked with $50 \mathrm{ml}$ lines on both the inner and outer surfaces (to facilitate urine collection and missing urine estimation) and a recording sheet, and were asked to collect all urine specimens during a $24 \mathrm{~h}$ period in the bottles (using the cups) as well as to record on the sheet the time of the start and end of the collection period (start usually 06.00-09.00 hours) and the estimated volume of all missing urine specimens. The recording sheet was reviewed by the staff when the collection bottles were handed in, and any missing information was obtained from subjects. In the 2006 survey, the height of urine in each bottle was 
measured and later converted into volume with an empirical formula based on repeated measurements of volume in identical bottles, as described in a previous study $^{(27)}$; in the 2007 survey, the total urine volume was directly measured using a graduated cylinder. We adjusted $24 \mathrm{~h}$ urine volume by self-reported collection time (calculated from the self-reported time of the start and end of the collection period) and missing urine volume; the utility of this adjustment has been indicated, at least in well-motivated populations ${ }^{(19)}$.

All urine samples taken over the $24 \mathrm{~h}$ period were carefully mixed, and several aliquots were taken and transported at $-20^{\circ} \mathrm{C}$ by car or aeroplane to ensure delivery to a laboratory (SRL Inc., Tokyo, Japan in 2006 and Mitsubishi Kagaku Bio-Clinical Laboratories Inc., Tokyo, Japan in 2007). All biochemical variables used in the present study were assayed at the laboratory within 1-2 d of collection to avoid significant degradation. Urea$\mathrm{N}$ concentrations were measured using the enzymatic assay method, $\mathrm{K}$ and $\mathrm{Na}$ using the electrode method, and creatinine (for the assessment for completeness of urine collection) using the enzymatic assay method. In-house quality control procedures for all assays were conducted at the respective laboratory. Total $24 \mathrm{~h}$ excretion was calculated by multiplying the measured concentration by the (adjusted) volume of $24 \mathrm{~h}$ urine. Urea-N content in $24 \mathrm{~h}$ urine was multiplied by $9 \cdot 08$, assuming that urea- $\mathrm{N}$ is in constant proportion (85\%) to total urinary $\mathrm{N}^{(12)}, 81 \%$ of ingested $\mathrm{N}$ is excreted through the urine ${ }^{(12,13)}$ and $\mathrm{N}$ constitutes $16 \%$ of protein. $\mathrm{K}$ content in $24 \mathrm{~h}$ urine was divided by $0 \cdot 77$, assuming that $77 \%$ of ingested $\mathrm{K}$ is excreted through the urine ${ }^{(14,15)}$. Na content in $24 \mathrm{~h}$ urine was divided by $0 \cdot 86$, assuming that $86 \%$ of ingested $\mathrm{Na}$ is excreted through the urine ${ }^{(14,16)}$.

On the day the collected $24 \mathrm{~h}$ urine sample was handed in, body height and weight were measured to the nearest $0 \cdot 1 \mathrm{~cm}$ and $0 \cdot 1 \mathrm{~kg}$, respectively, while the subject was wearing light clothes and no shoes. BMI was calculated as body weight $(\mathrm{kg})$ divided by the square of body height (m). Energy expenditure can be estimated as BMR multiplied by an appropriate physical activity level value ${ }^{(28)}$. BMR was estimated using measured body weight according to the FAO/WHO/United Nations University equation for women aged $18-30$ years ${ }^{(29)}$. In the absence of an accurate and comprehensive measure of physical activity, we could not assign each subject an appropriate physical activity level value. In our sample, self-reported time spent on sedentary activities was predominant compared with that spent on high-intensity activities, moderate-intensity activities and walking (mean: 16.44, $0 \cdot 06,0.25$ and $0.45 \mathrm{~h} / \mathrm{d}$, respectively) indicating a predominantly sedentary lifestyle, as described previously $^{(18)}$. We thus estimated energy expenditure as estimated BMR by physical activity level value for light activity $(1 \cdot 56)^{(29)}$. Considering the influence of body size (and physical activity) on the amount of food consumed and hence urinary excretion of nutrients, energy-adjusted values of biomarker-based estimates of nutrient intake (percentage of energy for protein and $\mathrm{mg} / 1000 \mathrm{~kJ}$ for $\mathrm{K}$ and $\mathrm{Na}$ ) were calculated using $24 \mathrm{~h}$ urinary excretion (with conversion for intake estimation, as described above) and estimated energy expenditure ${ }^{(17,30)}$.

\section{Statistical analysis}

All statistical analyses were performed with the SAS statistical software package version 8.2 (SAS Institute Inc., Cary, NC, USA). Using the PROC GLM procedure, linear regression models were constructed to examine the association of monetary cost of the self-reported diet (total and selected food groups) with biomarker-based estimates of nutrient intake (protein, $\mathrm{K}$ and $\mathrm{Na}$ ). For analyses, subjects were categorized into quintiles according to monetary cost of the self-reported diet. Mean values (with 95\% confidence intervals) of biomarkerbased estimates of nutrient intake were calculated by quintile of monetary cost of the self-reported diet. Adjustment was made for survey year (2006 or 2007) because of the differences in the procedure used to measure $24 \mathrm{~h}$ urine volume and in the laboratory used for biochemical measurements. For analysis of the monetary costs of individual food groups, adjustment was also made for the monetary costs of all other food groups (continuous). We tested for linear trends with increasing levels of monetary cost of self-reported diet by assigning each participant the median value for the category and modelling this value as a continuous variable. We also calculated the regression coefficient (and 95\% confidence interval) expressing changes of biomarker-based estimates of nutrient intake for an increment of monetary costs of 1 Japanese yen/1000 kJ of self-reported diet by multiple regression analysis (using the PROC REG procedure). All reported $P$ values are two-tailed and $P<0.05$ was considered significant.

\section{Results}

In total, 1105 of 1176 women undertook $24 \mathrm{~h}$ urine collection. For the present analysis, women aged 18-22 years were selected ( $n$ 1083). We then excluded women not completing survey questionnaires $(n 1)$ and those with extremely low or high reported energy intakes $(<2092$ or $>16736 \mathrm{~kJ} / \mathrm{d} ; n$ ). We further excluded those whose $24 \mathrm{~h}$ urine collection was considered incomplete ( $n$ 35) as assessed using information on urinary creatinine excretion and body weight based on a strategy proposed by Knuiman et al. $^{(31)}$ and as per our previous analysis ${ }^{(19)}$, which showed that only thirty-six $(5 \cdot 5 \%)$ of 654 Japanese female dietetic students were identified as having incomplete $24 \mathrm{~h}$ urine by the $p$-aminobenzoic acid check method and that this creatinine-based strategy was useful (sensitivity: 0•47; specificity: 0.99), at least in well-motivated populations 
where the proportion of incomplete urine is presumed to be small. The final analysis sample comprised 1046 women.

Basic characteristics of the subjects are shown in Table 1. Important contributors to total monetary diet cost were vegetables, fish, meat and confectioneries, followed by rice, dairy products and fruits. Pearson's correlation matrix of monetary costs of self-reported diet is shown in Table 2. Total monetary cost of self-reported diet was correlated relatively strongly with the monetary costs of vegetables and fish; modestly with those of meat, rice and fruits; and somewhat weakly with those of confectioneries and dairy products. Correlations among the monetary costs of food groups were low to modest.

Associations between monetary cost of self-reported diet and biomarker-based estimates of nutrient intake are shown in Table 3. Similar results were observed when monetary cost of self-reported diet was treated as a categorical variable (quintile) and as a continuous variable. Total monetary cost of self-reported diet was significantly positively associated with biomarker-based estimates of protein, $\mathrm{K}$ and $\mathrm{Na}$ intake. The monetary cost of vegetables was also significantly positively associated with all three nutrients, while the monetary cost of fish showed a significant and positive association with protein but not with $\mathrm{K}$ or $\mathrm{Na}$. Regarding the monetary costs of other foods, there were significant negative associations between the monetary cost of confectioneries and $\mathrm{Na}$ and between that of fruits and protein and $\mathrm{Na}$, and significant positive associations between that of dairy products and protein and $\mathrm{K}$.

\section{Discussion}

In the current preliminary study of young Japanese women, we found that total monetary cost of self-reported diet was positively associated with biomarker-based estimates of protein, $\mathrm{K}$ and $\mathrm{Na}$ intake. To our knowledge, the present study is the first to examine the relationship of monetary costs of the self-reported diet with biomarkerbased, rather than self-reported, estimates of dietary intake.

A limited number of observational studies in Europe have consistently shown that healthful diets are more

Table 1 Basic characteristics of 1046 Japanese women aged 18-22 years: subset of participants in the Japan Dietetic Students' Study for Nutrition and Biomarkers, 2006 and 2007

\begin{tabular}{lcr}
\hline Variable & Mean or \% & SD \\
\hline Age (years) & $19 \cdot 6$ & $1 \cdot 0$ \\
Body height (cm) & $158 \cdot 4$ & $5 \cdot 4$ \\
Body weight $(\mathrm{kg})$ & $53 \cdot 3$ & $7 \cdot 3$ \\
BMl $\left(\mathrm{kg} / \mathrm{m}^{2}\right.$ ) & $21 \cdot 2$ & $2 \cdot 5$ \\
Survey year $(\%)$ & $38 \cdot 9$ & \\
2006 & $61 \cdot 1$ & \\
2007 & & $3 \cdot 4$ \\
Biomarker-based estimates of nutrient intake & $13 \cdot 8$ & 98 \\
Protein (\% of energy) & 271 & 173 \\
K (mg/1000 kJ) & 462 & $18 \cdot 2$ \\
Na (mg/1000 kJ) & & $10 \cdot 2$ \\
Monetary costs of self-reported diet (Japanese yen*/1000 kJ) & $107 \cdot 6$ & $8 \cdot 8$ \\
Total & $17 \cdot 7$ & $8 \cdot 5$ \\
Vegetables & $16 \cdot 7$ & $6 \cdot 8$ \\
Fish & $16 \cdot 6$ & $3 \cdot 7$ \\
Meat & $12 \cdot 9$ & $5 \cdot 2$ \\
Confectioneries & $9 \cdot 3$ & $4 \cdot 9$ \\
Rice & $8 \cdot 7$ & \\
Dairy products & $5 \cdot 8$ & \\
Fruits & & \\
\hline
\end{tabular}

*1 Japanese yen $=0.0048 \mathrm{GBP}=0.0062 €=0.0095$ \$US in May 2008.

Table 2 Pearson's correlation matrix of monetary costs of self-reported diet (Japanese yen $/ 1000 \mathrm{~kJ}$ ) in 1046 Japanese women aged 18-22 years: subset of participants in the Japan Dietetic Students' Study for Nutrition and Biomarkers, 2006 and 2007

\begin{tabular}{lcccccrrr}
\hline & Total & Vegetables & Fish & Meat & Confectioneries & Rice & Dairy products & Fruits \\
\hline Total & - & 0.70 & 0.68 & 0.38 & 0.08 & -0.35 & 0.05 \\
Vegetables & & - & 0.35 & 0.04 & -0.13 & -0.07 & -0.06 \\
Fish & & & - & 0.18 & -0.14 & -0.06 & -0.09 \\
Meat & & & & - & -0.16 & -0.07 & -0.24 \\
Confectioneries & & & & & - & -0.41 & -0.07 \\
Rice & & & & & & -0.07 & -0.03 \\
Dairy products & & & & & & & -0.12 \\
Fruits & & & & & & & -0.07 \\
\end{tabular}

*1 Japanese yen $=0.0048$ GBP $=0.0062 €=0.0095 \$$ US in May 2008. 
Table 3 Biomarker-based estimates of nutrient intake according to quintile (Q) of monetary cost of self-reported diet in 1046 Japanese women aged 18-22 years*: subset of participants in the Japan Dietetic Students' Study for Nutrition and Biomarkers, 2006 and 2007

\begin{tabular}{|c|c|c|c|c|c|c|}
\hline \multirow{3}{*}{$\begin{array}{l}\text { Monetary costs of self-reported diet } \\
\text { (Japanese yent/1000 kJ) }\end{array}$} & \multicolumn{6}{|c|}{ Biomarker-based estimates of nutrient intake } \\
\hline & \multicolumn{2}{|c|}{ Protein (\% of energy) } & \multicolumn{2}{|c|}{$\mathrm{K}(\mathrm{mg} / 1000 \mathrm{~kJ})$} & \multicolumn{2}{|c|}{$\mathrm{Na}(\mathrm{mg} / 1000 \mathrm{~kJ})$} \\
\hline & Mean & $95 \% \mathrm{Cl}$ & Mean & $95 \% \mathrm{Cl}$ & Mean & $95 \% \mathrm{Cl}$ \\
\hline \multicolumn{7}{|l|}{ Total } \\
\hline Q1 [85·8]‡ & $13 \cdot 3$ & $12 \cdot 9,13 \cdot 7$ & 238 & 225,251 & 426 & 403,450 \\
\hline Q2 [97·1] & $13 \cdot 5$ & $13 \cdot 1,13 \cdot 9$ & 262 & 249,275 & 468 & 445,492 \\
\hline Q3 [106.9] & $14 \cdot 0$ & $13 \cdot 6,14 \cdot 4$ & 284 & 271,297 & 475 & 452,498 \\
\hline Q4 [115.6] & $13 \cdot 8$ & $13 \cdot 4,14 \cdot 2$ & 269 & 256,282 & 468 & 445,491 \\
\hline Q5 [131·4] & $14 \cdot 4$ & $14 \cdot 0,14 \cdot 8$ & 301 & 288,314 & 475 & 451,498 \\
\hline$P$ for trend $\S$ & \multicolumn{2}{|r|}{0.0005} & \multicolumn{2}{|c|}{$<0.0001$} & \multicolumn{2}{|r|}{0.011} \\
\hline $\begin{array}{l}\text { Regression coefficient }(95 \% \mathrm{Cl}) \| \\
P\end{array}$ & \multicolumn{2}{|c|}{0.0002} & \multicolumn{2}{|c|}{$<0.0001$} & \multicolumn{2}{|c|}{0.013} \\
\hline \multicolumn{7}{|l|}{ Vegetables } \\
\hline Q1 [7·7] & $13 \cdot 6$ & $13 \cdot 2,14 \cdot 0$ & 236 & 222,249 & 435 & 411,459 \\
\hline Q2 [11.6] & $13 \cdot 6$ & $13 \cdot 2,14 \cdot 0$ & 258 & 245,271 & 451 & 428,475 \\
\hline Q3 [15.6] & $13 \cdot 9$ & $13 \cdot 5,14 \cdot 3$ & 267 & 255,280 & 465 & 442,488 \\
\hline Q4 [20.6] & $13 \cdot 7$ & $13 \cdot 3,14 \cdot 1$ & 286 & 273,298 & 471 & 448,495 \\
\hline Q5 [30.2] & $14 \cdot 3$ & $13 \cdot 9,14 \cdot 7$ & 308 & 294,321 & 491 & 467,515 \\
\hline$P$ for trend & \multicolumn{2}{|r|}{0.032} & \multicolumn{2}{|c|}{$<0.0001$} & \multicolumn{2}{|r|}{0.002} \\
\hline $\begin{array}{l}\text { Regression coefficient }(95 \% \mathrm{Cl}) \\
P\end{array}$ & 0.008 & $\begin{array}{l}0.003,0.013 \\
0.002\end{array}$ & $2 \cdot 50$ & $\begin{array}{l}1 \cdot 91,3 \cdot 08 \\
0001\end{array}$ & $2 \cdot 05$ & $\begin{array}{l}0 \cdot 97,3 \cdot 13 \\
0 \cdot 0002\end{array}$ \\
\hline Fish & & & & & & \\
\hline Q1 [6.6] & $13 \cdot 3$ & $12 \cdot 9,13 \cdot 7$ & 273 & 260,287 & 446 & 422,469 \\
\hline Q2 [11.6] & $13 \cdot 5$ & $13 \cdot 1,13 \cdot 9$ & 263 & 250,276 & 450 & 427,473 \\
\hline Q3 [15.6] & $13 \cdot 8$ & $13 \cdot 4,14 \cdot 2$ & 272 & 260,285 & 489 & 466,511 \\
\hline Q4 [19.9] & $14 \cdot 1$ & $13 \cdot 7,14 \cdot 5$ & 276 & 263,289 & 481 & 458,504 \\
\hline Q5 [28.2] & $14 \cdot 3$ & $13 \cdot 9,14 \cdot 7$ & 269 & 256,282 & 448 & 424,472 \\
\hline$P$ for trend & & 0.002 & & .98 & & 0.74 \\
\hline $\begin{array}{l}\text { Regression coefficient }(95 \% \mathrm{Cl}) \\
P\end{array}$ & 0.009 & $\begin{array}{l}0.003,0.015 \\
0.002\end{array}$ & $-0 \cdot 11$ & $\begin{array}{l}-0 \cdot 79,0.58 \\
\cdot 76\end{array}$ & $0 \cdot 20$ & $\begin{array}{l}-1 \cdot 04,1 \cdot 45 \\
0 \cdot 74\end{array}$ \\
\hline Meat & & & & & & \\
\hline Q1 [7·5] & $13 \cdot 8$ & $13 \cdot 4,14 \cdot 2$ & 275 & 262,288 & 455 & 431,479 \\
\hline Q2 [11·8] & $13 \cdot 7$ & $13 \cdot 3,14 \cdot 1$ & 271 & 259,284 & 449 & 426,472 \\
\hline Q3 [15.2] & $13 \cdot 7$ & $13 \cdot 3,14 \cdot 1$ & 261 & 248,274 & 456 & 433,479 \\
\hline Q4 [19.4] & $13 \cdot 6$ & $13 \cdot 2,14 \cdot 0$ & 277 & 265,290 & 475 & 452,499 \\
\hline Q5 [26.8] & $14 \cdot 1$ & $13 \cdot 7,14 \cdot 5$ & 269 & 256, 282 & 477 & 454,500 \\
\hline$P$ for trend & & 0.35 & & 80 & & 0.09 \\
\hline $\begin{array}{l}\text { Regression coefficient }(95 \% \mathrm{Cl}) \\
P\end{array}$ & 0.005 & $\begin{array}{l}-0.001,0.011 \\
0.09\end{array}$ & -0.25 & $\begin{array}{l}-0 \cdot 96,0.45 \\
\cdot 48\end{array}$ & $1 \cdot 17$ & $\begin{array}{l}-0 \cdot 12,2 \cdot 46 \\
0 \cdot 07\end{array}$ \\
\hline Confectioneries & & & & & & \\
\hline Q1 [5.9] & $14 \cdot 1$ & $13 \cdot 7,14 \cdot 5$ & 270 & 256,284 & 461 & 436,485 \\
\hline Q2 [9.0] & $13 \cdot 9$ & $13 \cdot 5,14 \cdot 3$ & 267 & 255,280 & 478 & 455,502 \\
\hline Q3 [11.5] & $13 \cdot 8$ & $13 \cdot 4,14 \cdot 2$ & 269 & 256,282 & 480 & 457,503 \\
\hline Q4 [14.8] & $13 \cdot 9$ & $13 \cdot 5,14 \cdot 3$ & 280 & 267,293 & 460 & 436,483 \\
\hline Q5 [21.6] & $13 \cdot 4$ & $13 \cdot 0,13 \cdot 8$ & 267 & 254,281 & 434 & 409,459 \\
\hline$P$ for trend & & 0.07 & & .96 & & 0.036 \\
\hline $\begin{array}{l}\text { Regression coefficient }(95 \% \mathrm{Cl}) \\
P\end{array}$ & -0.007 & $\begin{array}{l}-0.015,0.001 \\
0.07\end{array}$ & 0.31 & $\begin{array}{l}-0 \cdot 64,1 \cdot 26 \\
\cdot 52\end{array}$ & $-1 \cdot 77$ & $\begin{array}{l}-3.51,-0.03 \\
0.046\end{array}$ \\
\hline Rice & & & & & & \\
\hline Q1 [4·8] & $13 \cdot 3$ & $12 \cdot 7,13 \cdot 9$ & 265 & 251,279 & 462 & 436,488 \\
\hline $\mathrm{Q} 2[7 \cdot 2]$ & $14 \cdot 0$ & $13 \cdot 6,14 \cdot 4$ & 274 & 261,286 & 451 & 428,473 \\
\hline Q3 [9.1] & $13 \cdot 8$ & $13 \cdot 4,14 \cdot 2$ & 271 & 258,283 & 463 & 440,486 \\
\hline Q4 [10.9] & $13 \cdot 9$ & $13 \cdot 5,14 \cdot 3$ & 266 & 253,278 & 475 & 452,499 \\
\hline Q5 [14.4] & $14 \cdot 0$ & $13 \cdot 4,14 \cdot 6$ & 278 & 264,292 & 462 & 436,487 \\
\hline$P$ for trend & & $0 \cdot 16$ & & $\cdot 43$ & & 0.64 \\
\hline $\begin{array}{l}\text { Regression coefficient }(95 \% \mathrm{Cl}) \\
P\end{array}$ & 0.015 & $\begin{array}{l}-0.001,0.030 \\
0.06\end{array}$ & $1 \cdot 01$ & $\begin{array}{l}-0 \cdot 83,2 \cdot 84 \\
\cdot 28\end{array}$ & $2 \cdot 54$ & $\begin{array}{l}-0 \cdot 81,5 \cdot 90 \\
0 \cdot 14\end{array}$ \\
\hline Dairy products & & & & & & \\
\hline Q1 [3.2] & $13 \cdot 5$ & $13 \cdot 1,13 \cdot 9$ & 249 & 235, 262 & 476 & 452,500 \\
\hline Q2 [5.6] & $13 \cdot 3$ & $12 \cdot 9,13 \cdot 7$ & 263 & 250,276 & 471 & 448,495 \\
\hline Q3 [7.7] & $13 \cdot 5$ & $13 \cdot 1,13 \cdot 9$ & 262 & 250,275 & 459 & 436,482 \\
\hline Q4 [10·4] & $14 \cdot 0$ & $13 \cdot 6,14 \cdot 4$ & 278 & 265,291 & 462 & 439,485 \\
\hline Q5 [16·1] & $14 \cdot 7$ & $14 \cdot 3,15 \cdot 1$ & 302 & 289,316 & 445 & 421,469 \\
\hline$P$ for trend & & $<0.0001$ & & 0001 & & 0.08 \\
\hline $\begin{array}{l}\text { Regression coefficient }(95 \% \mathrm{Cl}) \\
P\end{array}$ & 0.020 & $\begin{array}{l}0.010,0.030 \\
0.0001\end{array}$ & $3 \cdot 32$ & $\begin{array}{l}2 \cdot 12,4 \cdot 51 \\
0001\end{array}$ & $-1 \cdot 78$ & $\begin{array}{l}-3 \cdot 97,0.40 \\
0 \cdot 11\end{array}$ \\
\hline
\end{tabular}




\begin{tabular}{|c|c|c|c|c|c|c|}
\hline \multirow{3}{*}{$\begin{array}{l}\text { Monetary costs of self-reported diet } \\
\text { (Japanese yent/1000 kJ) }\end{array}$} & \multicolumn{6}{|c|}{ Biomarker-based estimates of nutrient intake } \\
\hline & \multicolumn{2}{|c|}{ Protein (\% of energy) } & \multicolumn{2}{|c|}{$\mathrm{K}(\mathrm{mg} / 1000 \mathrm{~kJ})$} & \multicolumn{2}{|c|}{$\mathrm{Na}(\mathrm{mg} / 1000 \mathrm{~kJ})$} \\
\hline & Mean & $95 \% \mathrm{Cl}$ & Mean & $95 \% \mathrm{Cl}$ & Mean & $95 \% \mathrm{Cl}$ \\
\hline \multicolumn{7}{|l|}{ Fruits } \\
\hline Q1 [1.4] & $14 \cdot 4$ & $14 \cdot 0,14 \cdot 8$ & 272 & 258,285 & 474 & 450,497 \\
\hline Q2 [3.0] & $14 \cdot 1$ & $13 \cdot 7,14 \cdot 5$ & 262 & 249,275 & 486 & 463,509 \\
\hline Q3 [4.5] & $13 \cdot 7$ & $13 \cdot 3,14 \cdot 1$ & 270 & 257,283 & 464 & 441,487 \\
\hline Q4 [6.6] & $13 \cdot 6$ & $13 \cdot 2,14 \cdot 0$ & 280 & 267,292 & 456 & 433,478 \\
\hline Q5 [11.6] & $13 \cdot 3$ & $12 \cdot 9,13 \cdot 7$ & 271 & 258,283 & 432 & 409,456 \\
\hline$P$ for trend & \multicolumn{2}{|r|}{0.0006} & \multicolumn{2}{|r|}{0.57} & \multicolumn{2}{|r|}{0.002} \\
\hline $\begin{array}{l}\text { Regression coefficient }(95 \% \mathrm{Cl}) \\
P\end{array}$ & -0.011 & $\begin{array}{l}-0.021,-0.001 \\
0.027\end{array}$ & 0.64 & $\begin{array}{l}-0 \cdot 53,1 \cdot 80 \\
0 \cdot 29\end{array}$ & $-2 \cdot 56$ & $\begin{array}{l}-4 \cdot 69,-0.42 \\
0.019\end{array}$ \\
\hline
\end{tabular}

${ }^{*} n 209$ in Q1, Q2, Q4 and Q5 and $n 210$ in Q3 for all monetary cost variables. Adjustment was made for survey year (2006 or 2007). For analysis of monetary costs of individual food groups, adjustment was also made for the monetary costs of all other food groups (Japanese yen/1000 kJ, continuous).

†1 Japanese yen $=0.0048$ GBP $=0.0062 €=0.0095$ \$US in May 2008.

$\ddagger$ Median (all such values).

$\S$ A linear trend test was used with the median value in each quintile as a continuous variable in linear regression analysis.

\|Expressing changes of biomarker-based estimates of intake of protein (percentage of energy), $\mathrm{K}$ ( $\mathrm{mg} / 1000 \mathrm{~kJ}$ ) or Na (mg/1000 kJ) for an increment of monetary costs of 1 Japanese yen/1000 kJ of self-reported diet. Adjustment was made for survey year (2006 or 2007 ). For analysis of monetary costs of individual food groups, adjustment was also made for the monetary costs of all other food groups (Japanese yen/1000 kJ, continuous).

expensive than less healthful diets, using diet cost and intake variables derived from self-reported dietary intake information $^{(4-9)}$. Conversely, monetary diet costs seem to be associated with both favourable and unfavourable dietary intake patterns in Japan; monetary cost of selfreported diet was positively associated with self-reported intakes of protein, dietary fibre and key micronutrients, including $\mathrm{K}$, but also positively associated with selfreported intake of $\mathrm{Na}$, fat, SFA and cholesterol and negatively with self-reported carbohydrate intake in young Japanese women ${ }^{(10)}$. The present findings of positive associations between total monetary costs of self-reported diet and biomarker-based estimates of protein, $\mathrm{K}$ and $\mathrm{Na}$ intake in young Japanese women are highly consistent with this previous self-report-based Japanese study ${ }^{(10)}$. Given that the common belief that a healthy diet costs more is supported by the above-mentioned European studies, which rely exclusively on self-reported dietary information, more research using biomarker-based estimates of dietary intake is needed. This need is emphasized by the importance of associations between dietary cost and intake to public health.

In the present study, vegetables and fish were not only the main contributors to total diet cost but also were relatively strongly correlated with it. Additionally, the monetary cost of vegetables was positively associated with protein, $\mathrm{K}$ and $\mathrm{Na}$, while that of fish was positively associated with protein, but not with K or Na. Thus, the positive associations of total monetary diet cost with protein, $\mathrm{K}$ and $\mathrm{Na}$ intake appear to be mainly accounted for by the monetary costs of vegetables and fish. While fruit (in addition to vegetables and fish) is an important contributor to total diet cost in European populations ${ }^{(8,9)}$, its contribution in the present Japanese study was quite small. This important difference, aside from differences in dietary habits, may be one explanation for the differences between Japanese and European studies on the associations between dietary cost and intake.

Several limitations of the present study warrant mention. First, our subjects were selected female dietetic students, not a random sample of Japanese people, and the exact response rate was unknown because of our recruitment procedure (although an approximate response rate was $56 \%$ ); these elements of the design may have produced recruitment bias. As such the subjects may have healthier dietary habits than the general population, although with regard to the self-reported intake of energy, protein, $\mathrm{K}$ and $\mathrm{Na}$ and $\mathrm{BMI}$ at least, mean values in the present study $(7406 \mathrm{~kJ} / \mathrm{d}, 60 \cdot 1 \mathrm{~g} / \mathrm{d}$, $1985 \mathrm{mg} / \mathrm{d}, 3626 \mathrm{mg} / \mathrm{d}$ and $21 \cdot 2 \mathrm{~kg} / \mathrm{m}^{2}$, respectively) were relatively comparable to those of a representative sample of Japanese women aged 20-29 years $(7000 \mathrm{~kJ} / \mathrm{d}, 62 \cdot 8 \mathrm{~g} / \mathrm{d}$, $1976 \mathrm{mg} / \mathrm{d}, 3661 \mathrm{mg} / \mathrm{d}$ and $20.5 \mathrm{~kg} / \mathrm{m}^{2}$, respectively) ${ }^{(32)}$. Additionally, students may not be directly paying the costs of food themselves. Thus, our results cannot be extrapolated to males or non-students and of course the general Japanese population, or even to the general student community.

Dietary data were collected using a self-administered semi-quantitative $\mathrm{DHQ}^{(20-23)}$. Although the validity of the DHQ appears reasonable with regard to commonly studied nutritional factors ${ }^{(20-23)}$, the DHQ is not designed specifically to measure monetary diet cost, as with other studies on this topic ${ }^{(4-11)}$. Additionally, food prices were derived from the National Retail Price Survey ${ }^{(25)}$ and websites of nationally distributed supermarket and fastfood restaurant chains. As this procedure provides only an approximation of actual diet costs, the results of the present study should be interpreted with caution. We note, however, that a similar methodology (relying on 
retail food prices as well as self-reported dietary intake information) has been used in all previous observational studies $^{(4-11)}$.

In the present study, a single $24 \mathrm{~h}$ urine sample was used, which is not optimal for characterizing individual habitual dietary intake and introduces random errors ${ }^{(33)}$. Nevertheless, errors in $24 \mathrm{~h}$ urine and hence biomarkerbased estimates of nutrient intake are thought to be independent of those in self-reported dietary intake (and retail food prices) and hence monetary costs of self-reported diet. This is an important and unique methodological characteristic of the present study, because in all previous studies on this topic (where both monetary diet costs and dietary intake are estimated based on self-reported dietary behaviour obtained by the same dietary assessment method) ${ }^{(4-11)}$, errors in selfreported dietary behaviour are shared by monetary diet cost and dietary intake.

Additionally, concern has been expressed regarding the precision of the correction factors used to estimate dietary intake from $24 \mathrm{~h}$ urine. Many variables may influence the percentage of ingested protein $(\mathrm{N}), \mathrm{K}$ and $\mathrm{Na}$ excreted in urine, including the absolute level of dietary intake, the season during which the balance study is conducted, race and cooking method ${ }^{(34)}$. Here, we used correction factors determined in carefully designed balance studies ${ }^{(12-16)}$, but the use of other correction factors should have little influence on the observed associations between dietary cost and intake. Nevertheless, estimates of biomarker-based nutrient intake themselves should be interpreted with caution, as they are largely dependent on the correction factors used.

Because energy expenditure was estimated by using physical activity level value for light activity, assuming a predominantly sedentary lifestyle in this population at the group level, energy expenditure of some subjects may have been underestimated ${ }^{(18)}$. However, because no significant difference in physical activity was seen among quintile categories of monetary diet cost (data not shown), it is unlikely that the use of physical activity level value for light activity for all subjects had any major impact on the observed associations between dietary cost and intake, notwithstanding that energy-adjusted biomarker-based estimates of nutrient intake may be on average overestimated.

Finally, several ${ }^{(35-39)}$ although not all ${ }^{(40)}$ intervention studies have reported that nutrient-dense diets consumed as a result of nutrition interventions were not more expensive than lower-quality diets. These intervention studies provided individual instructions on how to identify nutritious low-cost foods, how and where to make food purchases, and how to store and prepare the foods, possibly facilitating the consumption of a healthier diet at lower cost. The observational nature of the present study did not allow us to investigate directly if the cost of diet changed after nutritional intervention.
In conclusion, the current preliminary study of young Japanese women showed that total monetary costs of selfreported diet were positively associated with biomarkerbased estimates of protein, $\mathrm{K}$ and $\mathrm{Na}$ intake, and appeared largely due to the monetary costs of vegetables and fish. Contrary to the common public health belief that a healthy diet costs more, spending more money for foods may not necessarily ensure healthier diets, at least among young Japanese women. The association of monetary diet costs with dietary intake is an important public health topic, but information based on using objective measures of dietary intake is not available except for the present study. Thus, further research using objective biomarkers of dietary intake, such as serum carotenoid and fatty acid concentrations, would be of interest.

\section{Acknowledgements}

This work was supported by grants from the Ministry of Health, Labour, and Welfare, Japan. None of the authors has any conflict of interest to declare. K.M. contributed to the concept and design of the study, the study protocol, data collection and management; coordinated the fieldwork; formulated the hypothesis; analysed and interpreted the data; and wrote the manuscript. S.S. (a principal researcher of this project) contributed to the concept and design of the study, the study protocol, data collection and management, the writing and editing of the manuscript; and formulated the hypothesis. Y.T. and K.U. contributed to the concept and design of the study, the study protocol and data collection. All authors contributed to the preparation of the manuscript and approved the final version submitted for publication. The authors thank Keika Mine, Yoko Hosoi, Mami Itabashi, Tomono Yahata, Asako Ishiwaki and Kyoko Saito (National Institute of Health and Nutrition) for data collection.

\section{References}

1. Shepherd R (2002) Resistance to changes in diet. Proc Nutr Soc 61, 267-272.

2. Glanz K, Basil M, Maibach E, Goldberg J \& Snyder D (1998) Why Americans eat what they do: taste, nutrition, cost, convenience, and weight control concerns as influences on food consumption. J Am Diet Assoc 98, $1118-1126$.

3. Lennernas M, Fjellstrom C, Becker W, Giachetti I, Schmitt A, Remaut de Winter A \& Kearney M (1997) Influences on food choice perceived to be important by nationallyrepresentative samples of adults in the European Union. Eur J Clin Nutr 51, S8-S15.

4. Maillot M, Darmon N, Vieux F \& Drewnowski A (2007) Low energy density and high nutritional quality are each associated with higher diet costs in French adults. Am J Clin Nutr 86, 690-696.

5. Drewnowski A, Darmon N \& Briend A (2004) Replacing fats and sweets with vegetables and fruits: a question of cost. Am J Public Health 94, 1555-1559. 
6. Andrieu E, Darmon N \& Drewnowski A (2006) Low-cost diets: more energy, fewer nutrients. Eur J Clin Nutr 60, 434-436.

7. Drewnowski A, Monsivais P, Maillot M \& Darmon N (2007) Low-energy-density diets are associated with higher diet quality and higher diet costs in French adults. J Am Diet Assoc 107, 1028-1032.

8. Cade J, Upmeier H, Calvert C \& Greenwood D (1999) Costs of a healthy diet: analysis from the UK Women's Cohort Study. Public Health Nutr 2, 505-512.

9. Schroder H, Marrugat J \& Covas MI (2006) High monetary costs of dietary patterns associated with lower body mass index: a population-based study. Int J Obes (Lond) 30, 1574-1579.

10. Murakami K, Sasaki S, Okubo H, Takahashi Y, Hosoi Y \& Itabashi M (2007) Monetary costs of dietary energy reported by young Japanese women: association with food and nutrient intake and body mass index. Public Health Nutr 10, 1430-1439.

11. Darmon N, Briend A \& Drewnowski A (2004) Energydense diets are associated with lower diet costs: a community study of French adults. Public Health Nutr 7 , 21-27.

12. Bingham SA \& Cummings JH (1985) Urine nitrogen as an independent validatory measure of dietary intake: a study of nitrogen balance in individuals consuming their normal diet. Am J Clin Nutr 42, 1276-1289.

13. Kipnis V, Midthune D, Freedman LS, Bingham S, Schatzkin A, Subar A \& Carroll RJ (2001) Empirical evidence of correlated biases in dietary assessment instruments and its implications. Am J Epidemiol 153, 394-403.

14. Holbrook JT, Patterson KY, Bodner JE, Douglas LW, Veillon C, Kelsay JL, Mertz W \& Smith JC Jr (1984) Sodium and potassium intake and balance in adults consuming selfselected diets. Am J Clin Nutr 40, 786-793.

15. Tasevska N, Runswick SA \& Bingham SA (2006) Urinary potassium is as reliable as urinary nitrogen for use as a recovery biomarker in dietary studies of free living individuals. J Nutr 136, 1334-1340.

16. Hunter D (1998) Biochemical indicators of dietary intake. In Nutritional Epidemiology, 2nd ed., pp. 174-243 [W Willett, editor]. New York: Oxford University Press.

17. Murakami K, Sasaki S, Takahashi Y et al. (2008) Misreporting of dietary energy, protein, potassium and sodium in relation to body mass index in young Japanese women. Eur J Clin Nutr 62, 111-118.

18. Murakami K, Sasaki S, Takahashi Y \& Uenishi K, the Japan Dietetic Students' Study for Nutrition and Biomarkers Group (2007) Dietary energy density is associated with body mass index and waist circumference, but not with other metabolic risk factors, in free-living young Japanese women. Nutrition 23, 798-806.

19. Murakami K, Sasaki S, Takahashi Y et al. (2008) Sensitivity and specificity of published strategies using urinary creatinine to identify incomplete $24-\mathrm{h}$ urine collection. Nutrition 24, 16-22.

20. Sasaki S, Yanagibori R \& Amano K (1998) Self-administered diet history questionnaire developed for health education: a relative validation of the test-version by comparison with 3-day diet record in women. J Epidemiol 8, 203-215.

21. Sasaki S, Yanagibori R \& Amano K (1998) Validity of a selfadministered diet history questionnaire for assessment of sodium and potassium: comparison with single 24-hour urinary excretion. Jpn Circ J 62, 431-435.

22. Sasaki S, Ushio F, Amano K, Morihara M, Todoriki T, Uehara Y \& Toyooka T (2000) Serum biomarker-based validation of a self-administered diet history questionnaire for Japanese subjects. J Nutr Sci Vitaminol 46, 285-296.
23. Murakami K, Sasaki S, Takahashi Y, Okubo H, Hirota N, Notsu A, Fukui M \& Date C (2008) Reproducibility and relative validity of dietary glycaemic index and load assessed with a self-administered diet-history questionnaire in Japanese adults. Br J Nutr 99, 639-648.

24. Science and Technology Agency (2005) Standard Tables of Food Composition in Japan, 5th revised ed. Tokyo: Printing Bureau of the Ministry of Finance.

25. Price Statistics Office, Statistics Bureau (2004) National Retail Price Survey in Japan. http://www.stat.go.jp/data/ kouri/index.htm (accessed June 2007).

26. Livingstone MBE \& Black AE (2003) Markers of the validity of reported energy intake. J Nutr 133, 895S-920S.

27. Stamler J, Elliott P, Dennis B, Dyer AR, Kesteloot H, Liu K, Ueshima H \& Zhou BF, INTERMAP Research Group (2003) INTERMAP: background, aims, design, methods, and descriptive statistics (nondietary). J Hum Hypertens 17, 591-608.

28. Black AE, Coward WA, Cole TJ \& Prentice AM (1996) Human energy expenditure in affluent societies: an analysis of 574 doubly-labelled water measurements. Eur J Clin Nutr 50, 72-92.

29. Food and Agriculture Organization of the United Nations/ World Health Organization/United Nations University (1985) Energy and Protein Requirements. Report of a Joint FAO/WHO/UNU Expert Consultation. WHO Technical Report Series no. 724. Geneva: WHO.

30. Heitmann BL \& Lissner L (1995) Dietary underreporting by obese individuals: is it specific or non-specific? BMJ $\mathbf{3 1 1}$, 986-989.

31. Knuiman JT, Hautvast JG, van der Heyden L et al. (1986) A multi-centre study on completeness of urine collection in 11 European centres. I. Some problems with the use of creatinine and 4-aminobenzoic acid as markers of the completeness of collection. Hum Nutr Clin Nutr 40, 229-237.

32. Ministry of Health, Labour and Welfare of Japan (2008) The National Health and Nutrition Survey in Japan, 2005. Tokyo: Daiichi Shuppan Publishing Co., Ltd.

33. Bingham SA (2003) Urine nitrogen as a biomarker for the validation of dietary protein intake. J Nutr 133, 921S-924S.

34. Zhang J, Temme EHM, Sasaki S \& Kesteloot H (2000) Under- and overreporting of energy intake using urinary cations as biomarkers: relation to body mass index. $\mathrm{Am} \mathrm{J}$ Epidemiol 152, 453-462.

35. Goulet J, Lamarche B \& Lemieux S (2008) A nutritional intervention promoting a Mediterranean food pattern does not affect total daily dietary cost in North American women in free-living conditions. J Nutr 138, 54-59.

36. Ottelin AM, Lindstrom J, Peltonen M et al. (2007) Costs of a self-selected, health-promoting diet among the participants of the Finnish Diabetes Prevention Study. Diabetes Care 30, 1275-1277.

37. Raynor HA, Kilanowski CK, Esterlis I \& Epstein LH (2002) A cost-analysis of adopting a healthful diet in a family-based obesity treatment program. J Am Diet Assoc 102, 645-656.

38. Burney J \& Haughton B (2002) EFNEP: a nutrition education program that demonstrates cost-benefit. $J$ Am Diet Assoc 102, 39-45.

39. Mitchell DC, Shannon BM, McKenzie J, Smiciklas-Wright H, Miller BM \& Tershakovec AM (2000) Lower fat diets for children did not increase food costs. J Nutr Educ 32, 100-103.

40. Stender S, Skovby F, Haraldsdottir J, Andresen GR, Michaelsen KF, Nielsen BS \& Ygil KH (1993) Cholesterollowering diets may increase the food costs for Danish children. A cross-sectional study of food costs for Danish children with and without familial hypercholesterolaemia. Eur J Clin Nutr 47, 776-786. 